\title{
MITOS SILAT BEKSI BETAWI
}

\section{MYTHS IN BEKSI SELF-DEFENSE ARTS OF BETAWI}

\author{
Yuzar Purnama \\ Balai Pelestarian Nilai Budaya (BPNB) Jawa Barat \\ Jl. Cinambo No. 136 Ujungberung-Bandung 42094 Tep/Fax. \\ e-mail: yuzarpurnama@gmail.com
}

\begin{abstract}
Abstrak
Silat beksi adalah penamaan dunia persilatan pada masyarakat Betawi. Silat beksi merupakan ilmu bela diri maen pukulan dengan empat pertahanan tubuh dari serangan lawan. Ilmu bela diri ini merupakan percampuran antara jurus silat Betawi dengan jurus-jurus bela diri dari Negeri Cina. Silat beksi sampai sekarang masih tumbuh dan berkembang pada masyarakat Betawi dibuktikan dengan adanya 120 sanggar silat beksi di Jakarta, hal inilah yang menarik bagi penulis untuk mengkaji apa yang menyebabkan produk budaya ini dapat bertahan bahkan berkembang. Ruang lingkup penulisan mencakup, Apakah yang dimaksud masyarakat Betawi? Apakah silat beksi itu? Adakah mitos silat beksi? Penelitian ini menggunakan pendekatan kualitatif dengan metode penelitian deskripsi. Kesimpulan penelitian, silat beksi bagi masyarakat Betawi memiliki nilai keagungan dan keluhuran, sehingga untuk mengungkapkannya munculah mitos-mitos misalnya ilmu ini diajarkan oleh makhluk jelmaan macan putih atau harimau.
\end{abstract}

Kata kunci: mitos, Silat Beksi, dan masyarakat Betawi.

\begin{abstract}
Beksi silat is the name of the martial world in the Betawi community. Beksi silat is a martial arts style with four body defenses against opponents. This martial art is a mixture of Betawi and China martial arts. Beksi silat is still growing and developing in the Betawi community as evidenced by the existence of 120 Beksi silat studios in Jakarta. This becomes the writer's interest to examine the reason of this martial art to survive and even develop. The scope of writing includes how the Betawi people are, what Silat Beksi Is, and the myths in Silat Beksi. This study uses a qualitative approach with description research methods. The conclusion of this study is that the Silat Beksi for the Betawi people has the value of majesty and nobility, so that some myths revealed. For example, this art was taught by white tiger or tiger incarnation.
\end{abstract}

Keywords: myths, Silat Beksi, and Betawi society.

\section{A. PENDAHULUAN}

DKI Jakarta adalah kota metropolitan, ibu kota Republik Indonesia. Jakarta dapat dikatakan kota termegah, termewah, dan terkaya di NKRI. Hal itu wajar karena bagaimana pun ibu kota negara harus menjadi indentitas bangsa Indonesia di mata dunia dan kebanggaan seluruh bangsa Indonesia.
DKI Jakarta sebagai ibu kota negara merupakan kota yang sangat kompleks dan majemuk dalam berbagai hal di Indonesia. Namun demikian, Jakarta pada kenyataannya merupakan tempat yang memiliki khasanah budaya daerah yang relatif banyak seperti ondel-ondel, gambang keromong, rebana, orkes samrah, keroncong tugu, tanjidor, lenong, lagu 
kicir-kicir, tari topeng, yapong, tari cokek, cerita rakyat Si Pitung, Si Jampang, Nyai Dasima, Mirah dari Marunda, Murtado Macan Kemayoran, Juragan Boing, kuliner gabus pucung, laksa betawi, sayur babanci, sayur godog, soto betawi, ayam sampyok, asinan betawi, nasi uduk, kue cucur, kue rangi, kue talam, kue kelen, kue kembang goyang, kerak telor, sengkulun, putu mayang, andepite, kue ape, kue cente manis, kue pepe, kue dongkal, kue geplak, dodol betawi, dan roti buaya, minuman es selendang mayang, es goyang, dan bir pletok. Belum lagi dialek Jakarta atau dialek Betawi yang sangat kental dan khas.

Masyarakat Jakarta sangat kental dengan budaya masyarakat Betawi. Masyarakat ini dapat dikatakan sebagai masyarakat asli di wilayah Jakarta. Kini budaya masyarakat Betawi semakin terpinggirkan dan berada di pinggiran Kota Jakarta seperti di Jakarta Selatan, Jakarta Timur, Jakarta Utara, dan Jakarta Barat.

Namun yang menjadi kebanggaan bangsa Indonesia adalah di tengah hiruk pikuk dan hingar bingar kota metropolitan Jakarta ternyata budaya daerah atau budaya tradisional masyarakat Jakarta yaitu budaya tradisional masyarakat Betawi dapat bertahan dan berkembang terus sampai sekarang.

Salah satu budaya yang masih bertahan dan terus berkembang di Betawi adalah silat beksi. Silat beksi ini sangat kental pada masyarakat Betawi karena kehidupan mereka yang religius dengan ditandai moto: ngaji, salat, dan silat.

Penelitian ini ingin mengangkat kenapa silat beksi dapat bertahan dan berkembang pada masyarakatnya dengan mengambil judul Mitos dalam Silat Beksi Betawi.

Tujuan penelitian adalah untuk mendapatkan gambaran yang lengkap dan jelas tentang mitos dalam silat beksi Betawi. Adapun ruang lingkup penelitian dibatasi pada pembahasan tentang masyarakat Betawi, silat beksi, dan mitos dalam silat Beksi Betawi.
Heksa mengatakan bahwa mitos atau mitologi kerap berada di luar batas pemikiran manusia (2014:19). Pemahaman awal yang perlu disepakati tentang mitos adalah apa yang dikemukakan oleh Barthes, yakni mitos adalah sebuah sistem komunikasi. Dengan kata lain, mitos adalah sebuah pesan. Dengan demikian dapat dikatakan bahwa mitos adalah cara penandaan (signification) sebuah bentuk. Mitos tidak ditentukan oleh objek pesannya, tetapi oleh cara dia mengutarakan itu sendiri (Barthes, 2011:1520).

Betawi adalah sebutan pribumi yang bertempat tinggal di Jakarta. Etnis Betawi seperti halnya etnis lainnya di Indonesia tidak muncul sekaligus namun melalui proses yang panjang. Heru mengatakan bahwa dari tiga periode yaitu periode Sriwijaya, Kerajaan Sunda, dan Islam sebetulnya sudah dapat dikatakan bahwa dasar-dasar tentang terbentuknya etnis Betawi sudah menjelma. Hanya saja waktu itu, penyebutan istilah Betawi belum ada. Orang menyebut penduduk Sunda Kalapa yang sudah mengganti nama menjadi Jayakarta dengan istilah "wong Jakarta/orang Jakarta" (2014:14).

Silat beksi adalah salah satu maen pukulan yang tumbuh kembang pada masyarakat Betawi. Silat beksi ditemukan dan lahir pada tahun 1800 di Desa Dadap, Tangerang. Engkong Jidan, Lie Ceng Ok, dan H. Marhali adalah tokoh-tokoh pertama yang mengembangkan silat beksi ke daerah Barat dan Selatan Jakarta. Sehingga terus menyebar ke Petukangan melalui tangan Engkong Hasbullah, Engkong Nur, Engkong Simin, Engkong Jali sampai kepada H. Mahtum sekarang ini (Yahya, 2002:79).

Silat beksi memiliki ciri khas yaitu gaya pukulan terbalik atau celentang yang disebut loco boni; bermain jarak rapat; kecepatan dan kekuatan ledakan pukulan mengandalkan gerak refleks tangan dan daya pikir atau inteligensia si praktisi, disertai pemanfaatan tenaga gerak bahu dan pinggul; gerak atraktif meledak-ledak 
dan hentakan kaki ke bumi yang diistilahkan gedig; dan memiliki filosofi "mau pukul, ogah dipukul" (GJ. Nawi, 1983:74).

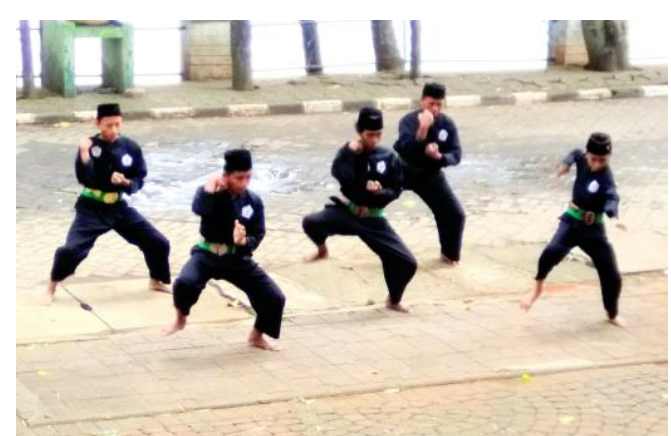

Gambar 1. Pesilat mempraktikan "gedig". Sumber: Dokumentasi BPNB Jawa Barat, 2018.

\section{B. METODE PENELITIAN}

Penelitian ini menggunakan metode deskripsi dengan pendekatan kualitatif. Wardi Bachtiar mengatakan bahwa metode deskriptif adalah kegiatan pengumpulan data dengan melukiskannya sebagaimana adanya, tidak diiringi dengan ulasan atau pandangan atau analisis dari penulis (1987:60-61). Metode penelitian deskriptif adalah penelaahan data yang memecahkan masalah yang tidak terbatas pada pengumpulan dan penyusunan sampai pada kesimpulan yang didasarkan atas penelitian (Surakhmad, 1982:19).

Dari anasir di atas dapat disimpulkan bahwa metode penelitian deskriptif adalah pengumpulan data dengan melukiskan apa adanya, tidak diiringi ulasan, pandangan, analisis dari peneliti, dan penelaahannya dapat memecahkan masalah yang dimulai dari pengumpulan data dan penyusunan data sampai kesimpulan atas dasar penelitian.

Adapun pendekatan penelitian kualitatif adalah prosedur penelitian yang menghasilkan data deskriptif berupa katakata tertulis atau lisan dari orang-orang dan perilaku yang dapat diamati (Bogdan, 1972:5). Moleong mengatakan bahwa pendekatan kualitatif adalah pendekatan yang didasarkan pada data yang dikumpulkan berupa kata-kata, gambar, dan bukan angka-angka. (1989:7).

Dari anasir di atas dapat disimpulkan bahwa pendekatan penelitian kualitatif adalah penelitian yang menggunakan data dari kata-kata tertulis, lisan, perilaku, gambar, dan bukan angkaangka.

Langkah-langkah dalam penelitian ini dimulai dengan pengambilan sumber pustaka dari buku-buku, internet, dan lainlain. Diteruskan dengan pengambilan data, pengklasifikasian data, analisis, dan penulisan.

\section{HASIL DAN BAHASAN \\ 1. Masyarakat Betawi}

Masyarakat Betawi adalah masyarakat asli yang sebagian besar berada di wilayah Jakarta. Wilayah lainnya yang didiami oleh masyarakat Betawi di antaranya di Bogor, Depok, Tangerang, dan Bekasi, namun kuantitasnya lebih kecil dibandingkan dengan masyarakat Betawi yang tinggal di Jakarta.

Masyarakat Betawi merupakan masyarakat keturunan dari berbagai etnis seperti etnis Jawa, Sunda, Bugis, Bali, Makassar, Ambon, Arab, India, Cina, Portugis, dan Belanda. Hal ini sejalan dengan pendapat Heru bahwa secara garis besar semua pakar sepakat bahwa etnis Betawi merupakan etnis yang lahir dari percampuran berbagai etnis suku bangsa yang berasal dari wilayah Nusantara bahkan bangsa seperti Portugis, India, Cina, Arab, Belanda, dan sebagainya (2014:13).

Menurut sejarawan Ridwan Saidi ${ }^{1}$, istilah "betawi" berasal dari nama flora atau tumbuhan yang ada di Nusantara. Istilah-istilah flora banyak digunakan sebagai nama tempat di Jakarta seperti Grogol, Gambir, Krekot, Bintaro, Makasar. Betawi, dan lain-lain. Pohon betawi adalah

\footnotetext{
${ }^{1}$ http://dunia-

kesenian.blogspot.co.id/2015/04/sejarah-asalusul-suku-betawi-dan.html, diakses tanggal 20-3-2018 pukul 09.47 WIB.
} 
sejenis tumbuhan perdu yang batangnya bulat seperti guling, mudah diraut, dan kokoh. Batang tumbuhan ini dahulu sering dibuat untuk kelengkapan senjata tradisional yaitu dibuat gagang untuk keris atau pisau.

Secara tertulis sebutan Betawi pertama kali terdapat dalam dokumen 1644 berupa testamen Nyai Inqua, janda tuan tanah Souw Beng Kong, Kapiten Tionghoa pertama di Batavia. Nyai Inqua menyebut seorang pembantu perempuannya adalah orang Betawi. Berdasarkan sumber sejarah berupa dokumen itu sebenarnya telah dikenal istilah "Orang Betawi". Dari bukti itu tentu dapat ditegaskan bahwa istilah etnis Betawi sudah muncul pada abad ke17 (Heru, 2014:14).

Bahasa yang digunakan masyarakat Betawi adalah bahasa Kreol yaitu bahasa Melayu Pasar ditambah dengan unsurunsur bahasa Sunda, Bali, Arab, Cina, dan bahasa dari Eropa. Bahasa Betawi memiliki ciri khas misalnya diakhiri dengan vokal "e" seperti gue, kemaren, siape, ape, babeh, die, gimane, dimane, kenape, kemane, dan lain-lain; diakhiri dengan akhiran (sufiks) -in misalnya ngapain, balikin, kembaliin, makanin, dudukin, biarin, dan lain-lain.

Produk budaya masyarakat Betawi pun banyak yang dipengaruhi dari budaya luar misalnya kesenian gambang keromong dipengaruhi budaya Cina, rebana biang dipengaruhi budaya Arab, tari yapong dipengaruhi tari jaipong dari Sunda, orkes samrah dipengaruhi budaya Melayu, kesenian keroncong tugu dipengaruhi oleh budaya Portugis dan Arab, serta tanjidor dipengaruhi budaya dari Belanda.

Masyarakat Betawi mayoritas beragama Islam, oleh karena itu ada istilah ngaji, solat, dan silat. Dalam kehidupan sehari-hari masyarakat Betawi kental sekali dengan dunia Islam. Mulai dari pakaian seperti pakaian koko, peci, kain, kopiah melekat dalam kehidupan seharihari yang diabadikan dalam pakaian adat masyarakat Betawi.

\section{Silat Beksi}

Istilah silat atau pencak silat pada masyarakat Betawi disebut maen pukulan. Banyak sekali jenis aliran maen pukulan di Betawi di antaranya beksi, kotek, trotok, cingkrik, ma'apil, kelabang nyebrang (sabeni), dan lain-lain (Yahya, 2002 : vii). Dari sekian banyak aliran maen pukulan ini yang paling banyak kuantitas pemain dan sanggarnya adalah maen pukulan beksi. Selanjutnya maen pukulan beksi ini disebut silat beksi.

Di dunia persilatan sering mendengar ada nama-nama jurus yang berasal dari perilaku hewan misalnya jurus pa monyet atau jurus kera, jurus ular, jurus kelabang, jurus engkang-engkang, jurus elang, dan lain-lain. Ada juga jurus yang diambil dari alam misalnya jurus saepi angin, jurus ujungan, jurus batra karang, dan lain-lain. Biasanya jurus-jurus ini diadopsi oleh para pesilat dengan memperhatikan dan mengamati perilaku hewan dalam mempertahankan diri dan menaklukkan lawan. Perilaku tersebut ditiru dan dipratikkan dalam latihan kanuragan. Lama-kelamaan setelah diulang-ulang dan dihapalkan serta dirasakan hasilnya jadilah sebuah jurus.

Jurus pa monyet atau jurus kera adalah gerakan jurus yang menyerupai perilaku monyet misalnya bercanda (mempermainkan), lincah, dan suka mencakar. Jurus ular adalah gerakan jurus yang menyerupai perilaku ular misalnya gerakannya lemah gemulai tapi dengan tiba-tiba tangan memukul bagian muka. Jurus batra karang adalah jurus badan yang kebal senjata tajam atau pukulan keras, badan tidak bergeming walaupun dipukul atau dihantam senjata tajam, dan sebagainya.

Dalam dunia persilatan atau pencak silat yang ada di Provinsi Jawa Barat saja, terdapat jurus-jurus persilatan seperti pa monyet, pa macan, jurus maung ngamuk, jurus badak Cihea, sepak kuda beger, caladi noktrok, dan lain-lain. Begitu pula dalam dunia bela diri seperti kung fu dari Cina dan silat beksi. 
Silat beksi lahir dari kemampuan orang-orang terpilih yang tiada hentihentinya melatih kepekaan indrawi, mengolah kelebihan atau kelenturan anatomi tubuh, dan belajar dari sebanyakbanyaknya pertanda alam yang ada di sekeliling mereka. Pertanda alam yang dimaksudkan adalah kehidupan alami berupa gerak debur ombak samudera, riak aliran sungai, hembusan angin sepoi-sepoi, rintik atau curah hujan, petir, kilat, geledek, gempa bumi, gunung meletus, atau memperhatikan pola gerak dunia fauna. Tidak sedikit dunia binatang mengilhami gerak atau jurus maen pukulan, apakah gerak macan, harimau, merak, kelabang, monyet, belalang cangcorang, dan sebagainya (Yahya, 2002:19).

Silat beksi terdiri atas dua kata yaitu "silat" dan "beksi". Kata silat berkaitan dengan salah satu ilmu bela diri yang tumbuh kembang di Nusantara. Silat atau pencak silat merupakan ilmu bela diri yang berkembang di Indonesia bahkan dapat dikatakan merupakan ilmu bela diri milik bangsa Indonesia. Pencak silat ini menyebar di Nusantara mulai dari Provinsi Aceh di utara Sumatra sampai Provinsi Lampung di selatan Pulau Sumatra, mulai dari Provinsi Banten di barat Pulau Jawa sampai Provinsi Jawa Timur di timur Pulau Jawa, Kalimantan, Sulawesi, Maluku, dan Nusa Tenggara.

Adapun kata "beksi" adalah istilah yang menandai silat yang ada di masyarakat Betawi di Jakarta. Istilah "beksi" berasal dari kata bie sie yaitu istilah yang dikatakan oleh pesilat bernama Lie Ceng Oek. Nama "bie sie" berubah menjadi kata "beksi" sesuai lidah masyarakat Betawi kala itu. Adapun kata "beksi" memiliki arti pertahanan empat penjuru, yaitu ilmu pertahanan manusia dari serangan arah barat, timur, utara, dan selatan. Selain itu, istilah beksi pun ada yang menyebutkan berasal dari kata "bhe si" istilah ini berasal dari Hokian. Istilah "bhe si" berarti kuda-kuda. Ada pula yang memberikan akronim Beksi dengan singkatan dari $\mathrm{B}=$ berbaktilah $\mathrm{E}=$ engkau $\mathrm{K}=$ kepada $\mathrm{S}=$ sesama $\mathrm{I}=$ insan.

Istilah beksi ${ }^{2}$ yang menamai ilmu bela diri asal Betawi ini secara etimologi atau asal usul kata. Terdapat banyak pendapat mengenai asal istilah beksi, namun menurut peneliti silat G.J. Nawi istilah itu perubahan dari kata aslinya bhe si, yang dalam bahasa Hokkien berarti 'kuda-kuda'. Lebih jauh (Nawi, 1983:63) mengatakan bahwa beksi berasal dari kata bek (bahasa Belanda) yang artinya pertahanan dan si (bahasa Cina) yang artinya empat. Pendapat lain berasal dari kosa kata bahasa Cina, bie si yang berarti pertahanan empat. Pendapat lain beksi merupakan transliterasi dari kata bhe si yang berasal dari kosa kata (fukian/fujian) di daerah Cina Selatan yang secara harfiah berarti kuda-kuda.

Silat beksi adalah salah satu aliran silat (Betawi: maen pukulan) khas Betawi. Aliran ini awalnya dikembangkan oleh masyarakat dari daerah Kampung Dadap, Kecamatan Kosambi, Tangerang. Selanjutnya, dikembangkan Lie Ceng Oek (1854-1951). Ia menggabungkan ilmu bela diri keluarganya dengan ilmu dari guruguru Betawinya, dan mengajarkan kepada murid-muridnya orang Betawi pesisir dan orang Cina Benteng di sekitar Kampung Dadap. Selanjutnya aliran silat ini menyebar ke daerah Petukangan Selatan, Jakarta Selatan, dan daerah Batujaya, Batuceper, Tangerang.

Salah seorang murid yang paling berbakat adalah Ki Marhali. Kemudian Ki Maharli mempunyai murid peranakan Betawi bernama $\mathrm{H}$. Gozali terus mengajarkan ilmunya kepada muridmuridnya di Petukangan, Jakarta Selatan, serta di Batujaya, Batuceper, Tangerang. Murid-murid utama H. Gozali antara lain Kong H. Hasbullah bin Misin, Kong M. Nur, Kong Simin, dan Kong Mandor Minggu, yang juga berguru pada $\mathrm{Ki}$

2 https://id.wikipedia.org/wiki/Silat_Beksi, diakses tanggal 25 Januari 2018 pukul 09.07 WIB. 
Marhali. Dari tokoh-tokoh ini kemudian silat beksi menyebar ke berbagai tempat.

Setidaknya terdapat 120 sanggar silat beksi di wilayah Jabodetabek. Pada tahun 2016 para anggota sanggar silat tersebut turut serta dalam Girli dan Beksi Village Festival 2016 di Kelurahan Batusari, Kecamatan Batuceper, Tangerang.

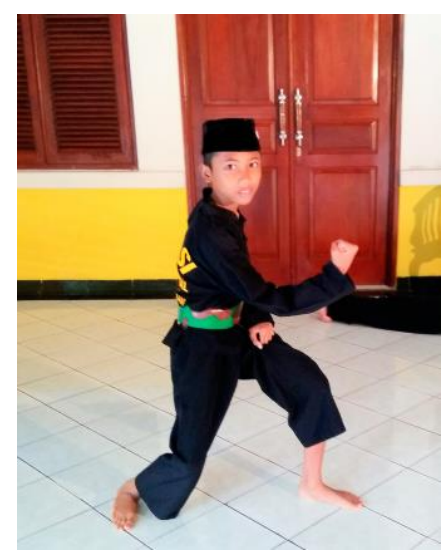

Gambar 2. Kuda-kuda silat beksi.

Sumber: Dokumentasi BPNB Jawa Barat, 2018.

Busana yang dikenakan para pesilat beksi saat tampil dalam sebuah pertunjukan atau turnamen umumnya menggunakan busana pangsi yang berwarna hitam-hitam; pakaian lengan panjang warna hitam yang longgar dan celana warna hitam yang longgar pula. Selain warna hitam, ada pakaian serupa dengan busana pangsi namun warna-warni seperti warna merah, kuning, biru, hijau, dan lain-lain. Warna-warni pakaian pangsi ini merupakan pakaian khas Betawi, karena salah satu pakaian adat betawi lakilaki adalah pangsi hitam dan warna-warni. Menurut seorang informan warna busana yang digunakan dalam silat beksi tidaklah memiliki makna tertentu. Warna-warni busana yang digunakan para pesilat ketika pertunjukan atau turnamen hanya sebatas untuk menarik hati para penonton. Dengan warna-warni akan membuat gerakan para pesilat lebih aktif dan menarik perhatian penonton. Lain lagi menurut informan lainnya bahwa warna itu menentukan tingkat atau level para pesilat. Warna merah biasanya malambangkan pesilat tersebut lebih mahir, unggul, dan berilmu tinggi.

Berbeda dengan pencak silat, dalam silat beksi tidak mengenal adanya musik pengiring gerakan jurus seperti dalam pencak silat di Nusantara. Dalam pencak silat atau silat biasanya ada jurus-jurus yang ditampilkan dengan iringan alat musik atau waditra yang disebut kendang pencak. Jurus-jurus ini disebut jurus kembang yang lainnya baru disebut isi. Alat musik pengiring pencak silat terdiri atas seperangkat kendang, gong, dan terompet. Berbeda dengan pencak silat, silat beksi tidak menggunakan perangkat musik atau waditra. Hal ini berkaitan dengan asal-muasal ilmu bela diri ini.

Silat beksi asalnya disebut bela diri maen pukulan kemungkinan berasal dari luar yaitu dari daratan Cina, walaupun sudah bercampur dengan jurus-jurus bela diri lokal yaitu silat Betawi, tapi unsur dari luarnya relatif cukup kuat. Apabila melihat ilmu bela diri dari Jepang yaitu karate, ilmu bela diri dari korea yaitu tae kwon do, ilmu bela diri dari Cina yaitu kung fu semuanya tidak menggunakan atau memanfaatkan alat musik pengiring, biasanya sebagai penanda gerakan jurus dengan mengatakan tanda-tanda berupa ucapan. Begitu pula pada silat beksi, penanda jurus menggunakan lafal ucapan saja.

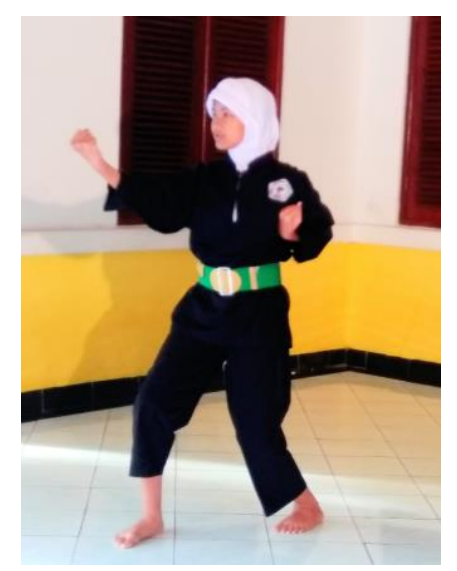

Gambar 3. Pesilat wanita sedang memperlihatkan jurus beksi.

Sumber: Dokumentasi BPNB Jawa Barat, 2018. 
Jurus-jurus silat beksi cukup banyak, sekitar 12 jurus dasar atau fundamental. Jurus-jurus ini tiap daerah berbeda, namun ada 3 jurus yang mendasar dan selalu ada di setiap daerah yaitu jurus beksi, jurus tancap, dan jurus gedig, misalnya di wilayah A memiliki jurus beksi, gedig, tancep, cauk, broneng, bandut, beksi satu, silem, lokbe, bolang baling, janda berias, dan jurus panca lima. Wilayah B memiliki jurus beksi, gedig, tancep, ganden, bandut/bandul, broneng, tingkes, Rusia pecah tiga, bolang baling, gebal, kebut dan jurus petir, demikian seterusnya.

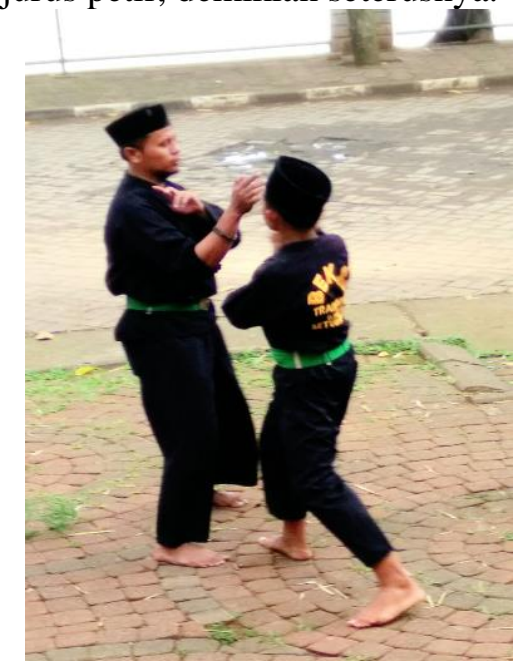

Gambar 4. Pesilat beksi sedang berduel.

Sumber : Dokumentasi BPNB Jawa Barat, 2018.

Menurut Yahya (2002:61-62), selain itu ada jurus-jurus kombinasi dan modifikasi. Meskipun kombinasi namun sifatnya inti dan pamungkas. Jurus kombinasi ini merupakan ciptaan para tokoh atau pakar silat beksi yang merupakan pengembangan dari 12 jurus dasar beksi. Jurus kombinasi ini di antaranya: jurus ganden bandut, bandut kurung, bandut tepok, bolang-baling, silem, lenggang barong/slipang/gebal, Rusia pecah tiga, kotek besi, jejel, jurus 21 kilat, dan jurus janda berias.

Setiap ilmu bela diri biasanya memiliki jurus lain selain tangan kosong seperti jurus menggunakan senjata tajam atau golok. Dalam silat beksi pun terdapat jurus yang menggunakan golok. Nama- nama jurus tersebut yaitu jurus golok satu (jurus satu), jurus golok satu (jurus dua), jurus golok satu (jurus tiga), jurus golok satu (jurus empat), jurus golok satu (jurus lima), jurus golok satu (jurus enam), jurus golok satu (jurus tujuh), jurus golok dua (jurus satu), jurus golok dua (Jurus dua), dan jurus golok dua (jurus tiga).

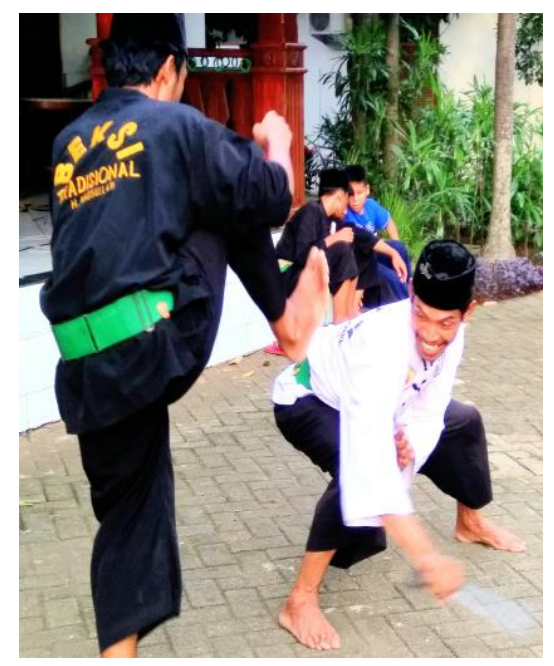

Gambar 5. Berduel menggunakan golok. Sumber: Dokumentasi BPNB Jawa Barat, 2018.

Silat beksi kini sudah berusia kurang lebih 2 abad, karena kelahirannya sekitar tahun 1800-an. Tumbuh kembang mata budaya ini sampai sekarang masih tampak. Dalam kurun 2 abad ternyata para tokoh beksi mulai dari perintis sampai penerus sekarang ini terekam di dalam hati para pelaku.

Silsilah guru silat beksi ini dari awal sampai generasi kini, dari generasi pertama sampai generasi ketujuh adalah sebagai berikut:

Generasi I : Raja Bulu dan Ki Jidan

Generasi II : Ki Lie Ceng Oek, Ki Tempang, Ki Muna, Ki Dalang Ji'ah

Generasi III ： Kong Marhali, Kong Godja lih

Generasi IV : Kong H. Hasbullah, Kong HM Nur, Kong Simin, Minggu, Salam Kalut, H. Mansyur, Muhammad Bopeng 


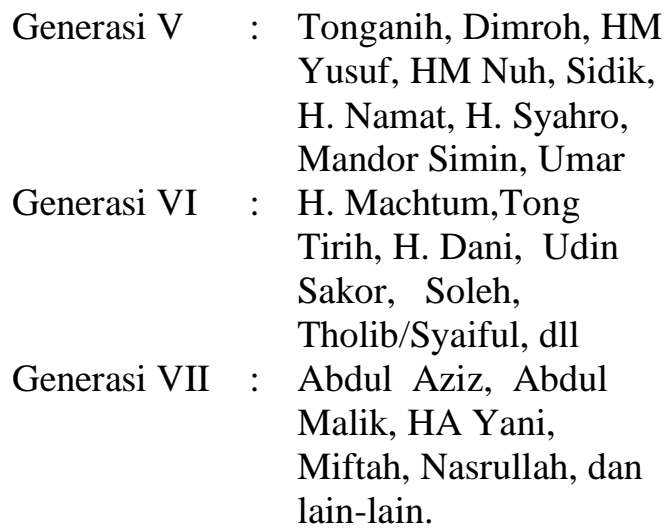

Generasi pertama mengajarkan ilmu silat beksi ke generasi kedua, generasi kedua mengajarkan ilmu ini ke generasi ketiga. Begitu seterusnya sehingga sampai pada generasi ketujuh, sekarang ini. Pengetahuan semacam ini jarang selengkap seperti ini, biasanya beberapa mata budaya selalu terputus untuk menelusuri siapa sebenarnya pendiri atau perintis mata budaya tersebut. Kalaupun diketahui pendirinya maka akan kesulitan untuk menentukan silsilah pendirinya sampai pada generasi sekarang secara berkesinambungan dari "A" sampai " $Z$ ".

Dari silsilah di atas dapat diketahui secara pasti bahwa guru besar atau orang yang pertama kali mempelajari dan mengembangkan ilmu bela diri silat beksi adalah Ki Jidan atau Ki Iban dan Raja Bulu. Ki Jidan adalah orang pribumi yang berasal dari etnis Betawi.

Pada perkembangan selanjutnya $\mathrm{Ki}$ Jidan mengajarkan ilmu bela diri silat beksi ke Lie Ceng Oek. Lie Ceng Oek adalah etnis keturunan Cina yang tinggal di sekitar Tangerang saat itu, dari sinilah terjadi percampuran ilmu bela diri silat beksi dari Ki Jidan Betawi dengan Lie Ceng Oek yang telah memiliki ilmu bela diri dari Cina. Percampuran ilmu bela diri ini selanjutnya dikembangkan dan diajarkan oleh Lie Ceng Oek kepada murid-muridnya. Dari murid-muridnya terus berkembang dari generasi ke generasi sampai sekarang ini.
Syarat menjadi seorang pesilat beksi tidaklah rumit dan bertele-tele hanya melakukan ritual rosulan atau ngerosul. Ritual rosulan atau ngerosul adalah tawasul disertai zikir, tahlil, dengan memanjatkan doa kepada Allah SWT agar dalam mempelajari beksi diberikan keridaan, kekuatan, dan kesabaran. Jika seorang pesilat beksi tidak menempuh ritual rosulan atau ngerosul maka akan berdampak pada matanya buta, kakinya patah, dan bantrok guru. Bantrok guru artinya seorang murid tidak disiplin dan tidak sopan kepada gurunya. Hal tersebut akan membuat gurunya tidak senang dan tidak akan menurunkan ilmunya kepada murid tersebut.

Dalam syarat menjadi pesilat beksi, ritual rosulan atau ngerosul ini dibagi menjadi tiga tahapan. Tahap pertama dilaksanakan ketika seseorang daftar menjadi murid silat beksi. Tahap kedua dilaksanakan jika pesilat beksi akan mendapatkan jurus keenam atau akan mendapatkan jurus broneng. Sedangkan tahap ketiga dilaksanakan jika seorang pesilat beksi selesai mendapatkan ilmu petir atau seseorang telah menyelesaikan seluruh jurus dalam ilmu bela diri silat beksi.

Setelah melaksanakan ritual rosulan atau ngerosul maka seorang pesilat berhak dan diperkenankan untuk mengajarkan ilmunya. Dalam artian pesilat beksi tersebut sudah dapat disebut sebagai guru karena sudah memiliki murid dan mengajarkan ilmu kepada muridnya.

Pelaksanaan ritual rosulan atau ngerosul biasanya diadakan setelah salat Isya yaitu mulai pukul 20.00 WIB sampai 22.00 WIB. Adapun tempatnya di halaman rumah atau ruang depan rumah Sang Guru. Para murid yang akan melaksanakan rosulan duduk melingkar di atas tikar pandan (Yahya, 2002:58).

Dimulailah ritual rosulan atau ngerosul diawali dengan membaca surat Alfatihah yang ditujukan kepada Nabi Muhammad SAW, sahabat Abu Bakar Ashshidiq, Umar bin Khatab, Usman bin 
Affan, Ali bin Abi Thalib, semua sahabat nabi dan tabiin, para wali, Syekh Abdulqadir Jaelani, dan seluruh pendahulu tokoh beksi. Kemudian dilanjutkan dengan membaca surat Alikhlas 3 kali, surat Alfalak, surat Annas, surat Albaqarah ayat 1-5, surat Albaqarah ayat 284-286, membaca ayat Kursi, zikir, tahlil, doa khusus, dan penutup.

Selesai berdoa semua murid diharuskan minum air kembang kemudian dibasuhkan ke muka, lengan, dada, dan kaki. Selanjutnya para murid dipersilakan menyantap makanan dan minuman yang ada di hadapannya, yaitu makanan dan minuman yang menjadi syarat setiap ritual rosulan atau ngerosul.

Perlengkapan rosulan atau ngerosul pada tahap pertama harus menyediakan pisang emas, kue tujuh rupa, kopi manis dan kopi pahit, teh manis, air putih, seperangkat pedupaan yaitu menyan putihmenyan item-stanggi-arang, kain putih dan kain merah, pisau lepit atau pisau cap garpu, minyak wangi, kembang tujuh rupa di dalam baskom tambah air dan minyak wangi, dan rujak tujuh rupa yaitu rujak yang terdiri atas buah tujuh rupa yang dipotong kecil-kecil kemudian ditambah air matang dan dicampur sirup. Perlengkapan ritual yang dapat dimakan dan diminum setelah acara selesai, disantap para murid yang mengikuti ritual ini.

Perlengkapan rosulan dan ngerosul tahap kedua sama dengan tahap pertama menyediakan pisang emas, kue tujuh rupa, kopi manis dan kopi pahit, teh manis, air putih, seperangkat pedupaan yaitu menyan putih-menyan item-stanggi-arang, kain putih dan kain merah, pisau lepit atau pisau cap garpu, minyak wangi, kembang tujuh rupa di dalam baskom tambah air dan minyak wangi, serta rujak tujuh rupa yaitu rujak yang terdiri atas buah-buahan tujuh rupa yang dipotong kecil-kecil kemudian ditambah air matang dan dicampur sirup.

Hanya saja ritual rosulan pada tahap kedua ini ditambah dengan susu dan pisang ambon. Begitu pula setelah ritual tahap kedua ini selesai maka sajian yang bisa dimakan dan diminum, dipersilakan dimakan oleh para murid yang mengikuti ritual ini. Rosulan tahap kedua ini disebut juga rosulan susu.

Perlengkapan ritual rosulan atau ngerosul pada tahap ketiga disajikan nasi putih, nasi tumpeng kuning, sayur daun kelor, ikan petek, sate cabe bawang terasi, dan ayam bekakak. Rosulan tahap ketiga ini disebut juga rosulan motong ayam.

\section{Asal-usul Silat Beksi}

Ada beberapa versi tentang asal muasalnya silat beksi. Versi-versi tersebut akan dibahas pada sub judul ini.

Versi pertama. Asal-usul Silat Beksi menurut guru besar Silat Beksi, Kong Nur Abdul Malik ${ }^{3}$. Konon ada seorang Tionghoa peternak yang tinggal di daerah Dadap Tangerang (sekarang dikenal dengan Cina Benteng) bernama Lie Ceng Oek. Sebenarnya keluarga Lie sendiri tidak mempunyai atau mewarisi bela diri apa pun dari negeri asalnya.

Konon, suatu ketika Lie sedang berteduh di sebuah gua di daerah tersebut. Lie berteduh sehabis mengangon ternak dan hujan turun.

Saat berteduh, Lie mendapat panggilan untuk masuk ke dalam gua tersebut, di dalam gua Lie Ceng Oek bertemu dengan sosok tinggi yang disebut oleh orang Betawi Ki Jidan. Mulai dari situlah Lie Ceng Oek belajar silat, setelah tamat belajar bela diri, Lie Ceng Oek mulai membangun reputasinya di dunia persilatan yang kala itu di daerah tersebut masih banyak para pendekar dan centeng terkenal.

Nama Lie Ceng Oek pun akhirnya terdengar ke seantero Betawi, terlebih ketika dia berhasil menjadi seorang saudagar kaya di daerahnya. Hingga akhirnya bertemulah Lie dengan Gozalih yang kala itu, diklaim sebagai pendekar silat terkenal dari salah satu aliran di

${ }^{3}$ http://ujungabad.blogspot.co.id/2012/05/sejar ah-silat-beksi-betawi.html, diakses tanggal 25 Januari 2018 pukul 09.17 WIB. 
Betawi. Kong Gozalih sendiri akhirnya belajar silat beksi setelah dikalahkan oleh Ceng Oek. Seiring dengan hal itu, kemudian juga masuk nama-nama besar yang kemudian dikenal sebagai guru dari tiga guru besar silat beksi yaitu, kyai Marhali yang terakhir kali bertempat di daerah Benda, Tangerang, mempunyai sejumlah murid yang tiga di antaranya menjadi guru besar dan akhirnya membawa nama silat beksi hingga dikenal seantero Jakarta.

Ketiga muridnya mengembangkan silat beksi di daerah Petukangan Jakarta Selatan. Sementara perguruan beksi yang berasal dari murid Kyai Marhali lainnya masih tersebar di daerah pelosok Tangerang hingga Cengkareng Jakarta Barat, yang hingga saat ini masih diajarkan secara turun temurun.

Versi kedua. Pada abad 19 sekitar tahun 1850-1860-an ${ }^{4}$, ada seorang tuan tanah di daerah Tangerang bernama Gow Hok Boen yang tinggal di Kampung Kosambi. Tuan tanah ini gemar bela diri dan menguasai ilmu kuntao atau kungfu. Sebagai tuan tanah, Tuan Gow punya sekian banyak centeng untuk membantunya. Kepala centengnya bernama Ki Kenong yang memiliki ilmu bela diri yang tinggi dan menguasai ilmu sihir yang dahsyat.

Tertarik dengan bela diri, Tuan tanah mengadakan sayembara untuk mencari jagoan yang lebih hebat dari kepala centengnya, untuk mendapat kedudukan menggantikan jabatan sebagai kepala centeng. Oleh karena itu setiap malam Minggu diadakan pertarungan untuk mengadu ilmu dan keberuntungan melawan Ki Kenong. Namun dari sekian banyak penantangnya belum ada satu pun yang berhasil mengalahkan Ki Kenong.

Tersebutlah ada seorang tukang singkong rebus disebut ancemon atau

\footnotetext{
${ }^{4}$ https://id-id.facebook.com/notes/forumbetawi-rempug-fbr-sejabodetabek/maenpukulan-betawi-perguruan-silatbeksi/98113506226/, diakse tanggal 25 Januari 2018 pukul 10.32 WIB.
}

singkong urap, bernama Pak Jidan yang setiap malam menjual singkong di tengah keramaian pertunjukan duel tersebut. Pak Jidan mengambil singkong dari hutan dekat tempat tinggalnya dan singkong tersebut tidak habis-habis dan seperti ada yang memelihara, namun karena di hutan Pak Jidan tidak ambil pusing. Suatu sore, ketika pak Jidan beristirahat di rumahnya dia didatangi oleh seorang pemuda yang protes karena singkong yang dia tanam dan pelihara di hutan diambil olehnya. Karena tidak tahu ada pemiliknya, Pak Jidan pun minta maaf.

Melihat keluguan dan kejujuran Pak Jidan serta hidupnya yang miskin, orang misterius itu menawarkan untuk membantu Pak Jidan dengan memberi pelajaran maen pukulan, tidak peduli waktu itu Pak Jidan sudah berumur sekitar 60-an.

Singkat kata, Pak Jidan menerima pelajaran maen pukulan sebanyak 8 jurus dan tiga atau empat lagi belum diajarkan, yang akan diajarkan oleh orang lain. Sebelum pergi orang misterius itu minta kemenyan dan berpesan bahwa dia bisa dipanggil jika Pak Jidan memerlukan dengan membakar kemenyan dan membaca mantra.

Ketika orang itu pergi, Pak Jidan melihat ekor macan tersembul dari balik jubahnya dan juga tengkuknya terlihat loreng-loreng seperti layaknya kulit harimau. Pak jidan pun terkejut dan maklum bahwa dia dikunjungi dan diajari maen pukulan oleh $\mathrm{Ki}$ Belang atau Siluman Macan Putih.

Malam selanjutnya, Pak Jidan berjualan seperti biasa di tengah pentas duel. Disebabkan karena jengkel dengan jagoan-jagoan yang tidak bayar sewaktu makan singkong daganganya, Pak Jidan menendang keranjang dagangannya dan melayang masuk ke tengah gelanggang. Tuan tanah Gow pun marah dan menyuruh orang menyeret Pak Jidan ke tengah arena dan memaksanya bertarung dengan $\mathrm{Ki}$ Kenong.

Di luar dugaan, Pak Jidan mampu mengalahkan $\mathrm{Ki}$ Kenong dengan ilmu 
yang diajarkan oleh $\mathrm{Ki}$ Belang itu. Menurut legenda, dengan jurus baroneng Pak Jidan melumpuhkan ilmu Ki Kenong yang terkenal dengan 'pukulan tangan berapi'. Ketika ditanya oleh Tuan Gow tentang ilmu yang dipakai oleh Pak Jidan, dia tidak tahu apa namanya. Lalu Tuan Gow Hok Boen menyebutnya beksi, artinya pertahanan empat mata angin.

Sejak itu terkenallah Pak Jidan yang diangkat sebagai kepala pengawal keamanan atau kepala centeng Tuan Gow. Berkat ilmu beksinya itu dia dapat mengalahkan kepala centeng Ki Kenong.

Versi ketiga. Di kampung bagian timur Tangerang hiduplah seorang laki-laki yang mahir bela diri bernama Raja Bulu. Beliau sudah berusia sekitar 63 tahun yang hidup berdua dengan anaknya yang gagu (bisu), karena istrinya sudah meninggal dunia.

Kehidupan Raja Bulu dapat dikatakan berkecukupan dengan pekerjaan mengajar silat dari kampung ke kampung. Namun aneh, anaknya sendiri tidak mau belajar silat padanya. Suatu ketika Raja bulu bertanya kepada anaknya mengapa dia tidak mau belajar maen pukulan. Dan jawabannya sungguh mengejutkan, "Belum tentu kalah dalam sambut-pukul dengan ayah".

Si ayah lalu mengetes dan terjadilah pertarungan. Dalam pertarungan tersebut, Raja Bulu keteter dan kewalahan menghadapi ilmu bela diri anaknya. Akhirnya si anak mengaku bahwa selama ini dia belajar maen pukulan di hutan. Selama ini ia dilatih oleh siluman macan putih. Oleh karena belum ada nama, Raja Bulu menyebut ilmu yang dikuasai oleh anaknya, Beksi, sebab gerakannya seperti segi empat dengan empat arah. Sejak itu Raja Bulu pun belajar pada anaknya dan diberikan mantra oleh anaknya agar bisa mengundang atau mempercepat kehadiran siluman macan putih. Adapun mantranya adalah sebagai berikut:

Ini kunciku ummiku,

Uliting Nabi ummi ulung Rosulullah, Hurosining Allah,
Nabi payungku,

Jibril tetepken aku,

Muhammad tutupku Allah,

Allah kunciku,

Laa ila haillallah Muhammadarrosulullah,

Pet empret (gedig tanah 3 kali).

Maung pundung,

Datengnya ampun,

Bumi rapet,

Braja sirep.

Gajah putih nyebrang lautan,

Datengnya tunduk menyembah di kaki aku,

La ilahailla anta sughanaka inni kuntum minazzhalimiin.

Kul inkutum tuhibbunallaha fattabiuuni yuhbibkumullah,

Wayaghfirulakum zunuubakum,

Wallahu ghafuururrahiem.

Selain mantra anaknya pun menyuruh ayahnya agar mengamalkan puasa 40 hari. Akhirnya Raja Bulu pun menguasai seluruh ilmu bela diri silat beksi, dan dengan berpuasa Raja Bulu mendapatkan ilmu pamungkas maen pukulan silat beksi. Setelah itu barulah Raja Bulu mengajarkan silat beksi kepada murid-muridnya. Silat beksi semakin berkembang sampai saat ini.

\section{Mitos dalam Silat Beksi}

Mitos mulanya dapat dipahami sebagai imajinasi sederhana dan primitif untuk menyusun serangkaian cerita, sebagaimana pendapat Ratna (2006:7). Dalam perkembangan yang lebih modern, mitos dipahami sebagai struktur cerita itu sendiri sehingga sebuah kisah secara keseluruhan dapat dikatakan mengemban amanat sebuah mitos tertentu. Pendapat itu sejalan dengan apa yang menjadi konsep mitos dalam pemahaman Levi-Strauss tidak lain adalah dongeng (Ahimsa-Putra, 2006:77).

Mitos dapat dikatakan sebagai cerita yang berada di luar logika. Cerita yang dikisahkan akan tampak benar-benar ada dan terjadi sehingga masyarakat 
memahaminya sebagai suatu yang benarbenar ada. Namun pada kenyataannya, cerita yang dianggap benar oleh masyarakat, tidak dapat diterima oleh akal sehat. Logika dan alam pikir manusia yang normal tidak dapat menerima kebenaran cerita tersebut, oleh sebab itu cerita atau kisah demikian disebut juga sebagai dongeng.

Mitos yang terdapat dalam silat beksi, di antaranya disebutkan oleh anaknya Raja Bulu yang gagu (bisu) bahwa ia mendapatkan ilmu bela diri tersebut di hutan. Ketika di hutan ia dilatih ilmu maen pukulan beksi oleh makhluk siluman macan putih.

Benarkah bahwa macan putih dapat mengajarkan sesuatu pada manusia? Apakah manusia yang meniru gerakan macan putih tersebut? Secara logika tidak mungkin seekor mancan apa pun termasuk macan putih mengajarkan sesuatu kepada manusia, apalagi ilmu yang diberikan olehnya pada masanya merupakan ilmu yang sangat penting dan bermanfaat untuk kehidupan. Untuk menjawab logika tersebut disebutkanlah bahwa yang mengajarkannya itu bukan macan beneran tapi macan jadi-jadian yaitu siluman macan putih. Jawaban tersebut untuk meredakan orang mencari tahu kebenaran seekor binatang dapat melatih dan mengajarkan ilmu bela diri kepada manusia. Namun jawaban yang diberikan tidaklah masuk akal atau di luar kebiasaan normal dalam kehidupan. Maka cerita yang menyebutkan bahwa silat beksi diturunkan kepada manusia melalui siluman macan putih hanyalah mitos belaka.

Mitos lainnya dapat dilihat ketika Raja Bulu mendapatkan mantra dan amalan puasa dari anaknya. Mantra dapat mengundang dan mempercepat kedatangan macan putih, sementara itu dengan mengamalkan puasa maka ilmu pamungkas bela diri silat beksi akan didapatkannya.

Dalam versi lain, mitos silat beksi muncul yaitu ketika $\mathrm{Ki}$ Jidan sering memanen singkong di hutan. Ternyata singkong tersebut tidak habis-habisnya, padahal setiap hari dipanen untuk berdagang. Keanehan muncul kenapa pohon singkong selalu tumbuh dan tidak penah habis?

Kemudian Ki Jidan mendapatkan tawaran untuk dilatih ilmu bela diri oleh sesorang yang misterius. Orang ini mengaku sebagai pemilik singkong yang ada di hutan, padahal selama ke hutan memetik singkong Pa Jidan tidak pernah menemukannya.

Orang misterius mengajari Pak Jidan 8 jurus, sisanya 4 jurus akan diajarkan oleh orang lain. Ketika Pak Jidan selesai belajar ilmu bela diri, orang tersebut pergi. Saat membelakangi, terlihat di bawah jubahnya ekor macan dan di pundaknya belangbelang seperti kulit harimau. Pertanyaan muncul, mungkinkah ada orang yang berekor panjang dan pundaknya belangbelang seperti kulit harimau?

Mitos muncul ketika Ki Jidan memperoleh ilmu bela diri silat beksi dari seekor macan dengan ciri ada ekor panjang di bawah jubahnya dan pundaknya belangbelang seperti harimau. Orang misterius pun mengaku bahwa kebun singkong yang ada di hutan adalah miliknya. Ialah yang menjaga dan memeliharanya selama ini, namun ketika pohonnya sering hilang maka ia marah sekali. Ditemuinya Ki Jidan untuk membalas kesalahannya. Namun dengan kerendahan hati, Ki Jidan meminta maaf karena selama ini dia tidak mengetahui bahwa kebun singkong di hutan ada pemiliknya.

Akhirnya orang misterius itu mau melatih Ki Jidan karena melihat keluguan, kejujuran, dan kemiskinannya. Kejadian di luar logika pun muncul ketika orang misterius itu minta kemenyan dan ia menitip pesan jika butuh bantuannya tinggal bakar kemenyan dan baca mantramantra. Jadi selama ini Ki Jidan belajar ilmu bela diri dari siluman Macan atau macan jadi-jadian. Adapun mantra yang diajarkan orang misterius kepada Ki Jidan adalah sebagai berikut:

\section{Asian kaula Si Macan Putih}




\section{Macan putih mangka asih \\ Odeng engang tiwuan \\ Sireupeun si teuweul tengah \\ Biwirku wesi letahu waja \\ Nunggah geugeuh dibeungeut kaula \\ Si Macan anakan \\ Tungkul kairud tanggah ku pari basah \\ Anggrek kamaya ngaraning pamor \\ Beurpes Beurpes Beurpes ku bayu sia sorangan \\ Laa ila ha illallah Muhammadarra- sullullah.}

Kata orang misterius itu, amalkan mantra itu sepenuh hati kemudian ditambah dengan mengamalkan puasa selama 40 hari, niscara bukan hanya mahir maen pukulan, tapi juga kebal dari semua senjata tajam.

Mengamalkan mantra dengan puasa 40 hari seperti anjuran orang misterius tadi yang dapat mengkondisikan seseorang kebal terhadap senjata tajam merupakan salah satu mitos yang tumbuh subur pada masyarakat terutama masyarakat pedesaan baik pada zaman dulu maupun sekarang di Nusantara.

Dalam versi yang lain, mitos muncul dalam silat beksi ketika dua orang tokoh utama silat beksi yakni Ki Jidan dan Lie Ceng Oek sedang memberi dan menuntut ilmu. Ki Jidan memberikan ilmu bela diri silat beksi kepada murid pertamanya yaitu Lie Ceng Oek. Namun mitos muncul ketika kegiatan pembelajaran ilmu bela diri terjadi saat Lie Ceng Oek sedang berteduh di gua sehabis mengangon ternak dan kehujanan. Lie Ceng Oek mendengar panggilan dari dalam gua.

Ternyata Ki Jidanlah yang memanggil Lie Ceng Oek ke dalam untuk mengajarkan ilmu bela diri silat beksi. Pertanyaan muncul, kenapa Ki Jidan ada dalam gua? Apakah selama ini Ki Jidan bertempat tinggal di dalam gua? Pertanyaan ini sulit terjawab namun dalam dunia persilatan hal tersebut lumrah dan biasa terjadi. Hal tersebut sebagai upaya untuk memperlihatkan kepada orang bahwa ilmu bela diri sangat agung, luhur, dan sakral.

\section{PENUTUP}

Semua makhluk hidup di permukaan bumi akan beradaptasi dengan lingkungan hidupnya. Manusia, binatang, tumbuhan pun akan beradaptasi dengan lingkungannya untuk mempertahankan hidup. Makhluk yang tidak sanggup beradaptasi dengan lingkungan lambat laun akan tersisih dan punah.

Makhluk hidup yang dapat beradaptasi misalnya hewan seperti domba dapat hidup di daerah sejuk dengan bulunya yang tumbuh sedang, kambing dapat menyesuaikan dirinya dengan lingkungan di daerah panas dengan bulunya yang tipis, dan biri-biri bisa menyesuaikan dengan lingkungan hidupnya yang dingin di daerah bersalju dengan bulunya yang tebal. Padahal domba, kambing, dan biri-biri dulunya satu nenek moyang. Adapun contoh hewan yang tidak dapat menyesuaikan diri dengan lingkungannya dan berakhir dengan kepunahan di antaranya hewan purba seperti dinosaurus, tyrex, dan sebagainya.

Salah satu bentuk adaptasi makhluk hidup terhadap lingkungannya adalah usaha mempertahankan diri dan melindungi dari makhluk hidup lainnya, misalnya manusia dalam sejarahnya harus mempertahankan diri dari serangan binatang buas dan sesama manusia yang berniat jahat.

Bentuk pertahanan diri ini dapat dilakukan dengan berbagai cara seperti menciptakan kekuatan diri, dengan senjata, dan dengan keterampilan atau keahlian tertentu. Kekuatan diri manusia dapat diolah dengan selalu melatih diri dengan berolah raga seperti berlari, berenang, fitnes, dan lain sebagainya. Mempertahankan diri dengan senjata dimulai dari penciptaan senjata sederhana seperti tombak, panah, ketapel, klurit, golok, badik, keris, kujang, pedang sampai pada senjata yang modern dan dapat membunuh secara masal misalnya menciptakan pistol, granat, senapan otomatis, tank baja, roket, peluru kendali, bom atom, bom nuklir, dan bom neutron. 
Adapun upaya yang ketiga untuk melindungi diri dari serangan musuh atau lawan yaitu dengan menciptakan keterampilan atau keahlian seperti ilmu bela diri pencak silat, yudo, karate, tae kwon do, kung fu, gulat, tinju, benjang, ujungan, dan lain sebagainya.

Ilmu bela diri ini tidak tumbuh dengan sendirinya tapi harus diciptakan oleh seseorang atau kelompok orang. Baik penciptaan maupun pengembangan harus disertai konsentrasi, pengetahuan, pengalaman, dan wawasan. Dengan melihat fenomena alam seperti ombak laut, batu karang yang ada di lautan, angin topan dapat menjadi ilham untuk menciptakan jurus, begitu pula perilaku hewan ketika sedang berkelahi seperti macan, monyet, burung dapat pula menjadi ilham untuk meciptakan jurus bela diri.

Beksi tercipta sebagai upaya manusia untuk mempertahankan dan melindungi diri dari serangan lawan baik manusia yang berniat jahat maupun serangan binatang buas. Jurus-jurus dalam silat beksi diilhami dari pengalaman dan pengetahuan lingkungannya.

Jurus-jurus dalam silat beksi yang penuh konsentrasi dengan mata melotot agar dapat melihat gerak-gerik lawan dan jangan sampai kecolongan disertai gerakan kaki yang dihentak-hentakan ke tanah "gedig" terbukti menimbulkan pukulan yang cepat dan kuat. Oleh karena itu, pantas saja IPSI tidak memperbolehkan pesilat beksi tampil untuk bertanding dengan pesilat lainnya.

Silat beksi dan ilmu bela diri lainnya sudah teruji ampuh dan dapat diandalkan sebagai ilmu bela diri yang dapat melindungi dan mempertahankan diri dari serangan musuh. Namun hampir setiap ilmu bela diri akan muncul mitos-mitos terutama berkaitan dengan asal-usul atau sejarah kelahirannya. Mengapa demikian?

Mitos dalam silat beksi di antaranya disebutkan bahwa yang pertama mengajarkan ilmu ini adalah seekor macan putih jadi-jadian atau siluman macan putih. Kemudian orang yang tidak melakukan amalan rosulan atau ngerosul akan buta mata, patah kaki, dan bantrok guru. Selanjutnya bakaran kemenyan dan pembacaan/pelafalan mantra dapat mendatangkan siluman macan putih dan mempercepat penyelesaian jurus-jurus silat beksi.

Mitos-mitos ini muncul untuk memperlihatkan kepada masyarakat bahwa ilmu bela diri silat beksi adalah ilmu yang agung, luhur, dan mulia. Selain itu mitosmitos ini dimunculkan dengan maksud tertentu, salah satunya adalah untuk menarik hati orang lain agar tertarik mempelajari dan menguasai ilmu bela diri ini.

Hasil penelitian ini diharapkan dapat bermanfaat bagi semua kalangan, khususnya bagi peminat budaya. Penulis pun mengucapkan terima kasih yang sebesar-besarnya kepada semua pihak yang telah membantu pelaksanaan penelitian ini.

\section{DAFTAR SUMBER}

\section{Jurnal}

Biopsi, Heksa. 2014.

"Mitos Oheo dan Asas Hubungan dalam Konsep O Rapu, Menguak Posisi Perempuan dalam Keluarga Suku Tolaki" dalam Patanjala Volume 6 Nomor 1 Maret 2014. Hlm. 381-398.

Erwantoro, Heru. 2014.

"Etnis Betawi; Kajian Historis" dalam Patanjala Volume 6 Nomor 1. Maret 2014. Hlm. 1-16.

\section{Buku}

Ahimsa-Putra, Heddy Shri. 2006. Strukturalisme Levi-Strauss, Mitos, dan Karya Sastra. Yogyakarta: Kepel Press.

Bachtiar, DR. Wardi. 1997.

Metode Penelitian Ilmu Dakwah. Pamulang Timur Ciputat: Logos Wacana Ilmu.

Barthes, Roland. 2010.

Imaji, Musik, Teks: Analisis Semiologi atas Fotografi, Iklan, Film, Musik, Alkitab, Penulisan dan Pembacaan serta Kritik Sastra. Agustinus Hartono (penerjemah).Yogjakarta: Jalasutra. 
Bogdan, Robert C. 1972.

Participant Oberservation in Organizational Settings, Syracuse, N.Y. : Syracuse Univercity Press.

Moleong, DR. Lexy J. 1989.

Metodologi Penelitian Kualitatif. Bandung : Remaja Karya.

Nawi, GJ. 1983.

Maen Pukulan; Pencak Silat Khas Betawi. Jakarta : Yayasan Pustaka Obor Indonesia.

Ratna, Nyoman Kutha. 2006.

Teori, Metode, dan Teknik Penelitian Sastra: dari Strukturalisme hingga Pastrukturalisme, Perspektif Wacana Naratif. Yogyakarta: Pustaka Pelajar.

Saputra, Yahya dll. 2002.

Beksi; Maen Pukulan Khas Betawi. Jakarta : Gunung Jati.

Surakhmad, Winarno. 1982.

Penelitian Dasar Metode Teknis. Bandung: Tarsito.

\section{Internet}

http://dunia-kesenian.blogspot.co.id/2015/

04/sejarah-asal-usul-suku-betawi-

dan.html, diakses tanggal 20-3-2018 pukul 09.47 WIB.

http://ujungabad.blogspot.co.id/2012/05/sejara h-silat-beksi-betawi.html, diakses tanggal 25 Januari 2018 pukul 09.17 WIB.

https://id.wikipedia.org/wiki/Silat_Beksi, diakses tanggal 25 Januari 2018 pukul 09.07 WIB. 
